\title{
Diagnostic challenges to determine the cause of pulmonary hypertension in a patient with heart failure with preserved ejection fraction and borderline pulmonary artery wedge pressure
}

\author{
Katarzyna Pieniak ${ }^{1 *}$, Aleksandra Gąsecka ${ }^{1 *}$, Arkadiusz Pietrasik', Piotr Scisło1, Szymon Darocha², \\ Marta Banaszkiewicz², Marcin Kurzyna ${ }^{2}$, Agnieszka Kapłon-Cieślicka' ${ }^{1}$ \\ ${ }^{1} 1^{\text {st }}$ Chair and Department of Cardiology, Medical University of Warsaw, Warszawa, Poland \\ ${ }^{2}$ Chair and Department of Pulmonary Circulation, Thromboembolic Diseases and Cardiology, Center of Postgraduate Medical Education, European Health Center, \\ Otwock, Poland \\ *Both authors equally contributed to the study
}

\author{
Correspondence to: \\ Agnieszka Kapłon-Cieślicka, \\ $\mathrm{MD}, \mathrm{PhD}$, \\ $1^{\text {st }}$ Chair and Department \\ of Cardiology, \\ Medical University of Warsaw, \\ Banacha 1A, 02-097 Warszawa, \\ Poland, \\ phone: +48225991958, \\ e-mail: \\ agnieszka.kaplon@gmail.com \\ Copyright by the Author(s), 2022 \\ DOI: 10.33963/KP.a2021.0173 \\ Received: \\ October 10, 2021 \\ Accepted: \\ December 6, 2021 \\ Early publication date: \\ December 6, 2021
}

Pulmonary hypertension $(\mathrm{PH})$ related to left heart disease (LHD) accounts for 65\%-80\% of $\mathrm{PH}$ cases [1]. LHD may lead to isolated post-capillary $\mathrm{PH}$, or combined post- and pre-capillary PH ("reactive" $\mathrm{PH}$ ) [2]. In the case of mixed $\mathrm{PH}$, a primary cause of the pre-capillary component (arterial PH or chronic thromboembolic $\mathrm{PH}$ [CTEPH]) must be considered due to potential targeted treatment [3]. We highlight here diagnostic challenges in this clinical scenario.

A 75-year-old man with exertional dyspnea (New York Heart Association [NYHA] class III), a history of myocardial infarction treated with stent implantation in the circumflex artery, moderate-severe mitral regurgitation, and four hospitalizations for right ventricular (RV) heart failure (HF) in the preceding year was admitted for diagnostic work-up. Echocardiography showed enlargement of both atria (left atrial volume index, $53 \mathrm{ml} / \mathrm{m}^{2}$; right atrial area, $\left.23 \mathrm{~cm}^{2}\right)$; normal left ventricular (LV) ejection fraction (EF) (62\%); increased LV filling pressures (E wave velocity, $1.1 \mathrm{~m} / \mathrm{s}$, E/e' ratio 13) with restrictive mitral inflow pattern (E/A ratio, 3.7) despite normal lateral mitral annulus velocity $\left(\mathrm{e}^{\prime}\right)(12 \mathrm{~cm} / \mathrm{s})$, and close-tonormal septal e' $(6 \mathrm{~cm} / \mathrm{s})$. RV systolic function was normal. He had moderate mitral regurgitation (MR), mild tricuspid regurgitation (TR; TR peak velocity [TRV], $3.5 \mathrm{~m} / \mathrm{s}$ ), and a dilated pulmonary artery with shortened acceleration time $(67 \mathrm{~ms}$ ) with midsystolic notching (Figure $1 \mathrm{~A})$. N-terminal pro-brain natriuretic peptide (NT-proBNP) concentration was $583 \mathrm{pg} / \mathrm{ml}$. The electrocardiogram showed atrial fibrillation and LV hypertrophy. The HFA-PEFF criteria were met (6 points in the HFA-PEFF score).

Exercise echocardiography was performed revealing a rapid increase in TRV (to $4.3 \mathrm{~m} / \mathrm{s}$ at 50 Watt), increase in TR severity (to moderate) and an RV basal diameter (from 3.8 to $4.4 \mathrm{~cm}$ ). There were no LV systolic abnormalities and no increase in MR severity. Regarding LV diastolic function, lateral $\mathrm{e}^{\prime}$ increased to $14 \mathrm{~cm} / \mathrm{s}$, while septal $\mathrm{e}^{\prime}$ decreased to $5 \mathrm{~cm} / \mathrm{s}$, with an average E/e' of 15 (Figure 1A). Coronary angiography revealed no significant lesions (Figure 1B). Computed tomography angiography excluded acute pulmonary embolism and CTEPH (Figure 1C).

The patient was diagnosed with heart failure with preserved EF. However, a significant increase in TRV during exercise, disproportionate to a relatively small increase in the $E / \mathrm{e}^{\prime}$ ratio, suggested the concomitant presence of pre-capillary $\mathrm{PH}$. Right heart catheterization (RHC) demonstrated mean pulmonary arterial pressure (mPAP) of $30 \mathrm{~mm} \mathrm{Hg}$ (confirming $\mathrm{PH})$, with pulmonary artery wedge pressure (PAWP) of $13 \mathrm{~mm} \mathrm{Hg}$ and pulmonary vascular resistance (PVR) of 5 Wood units (indicative of pre-capillary PH) [3]. However, repeated $\mathrm{RHC}$ in the reference center showed mPAP of 

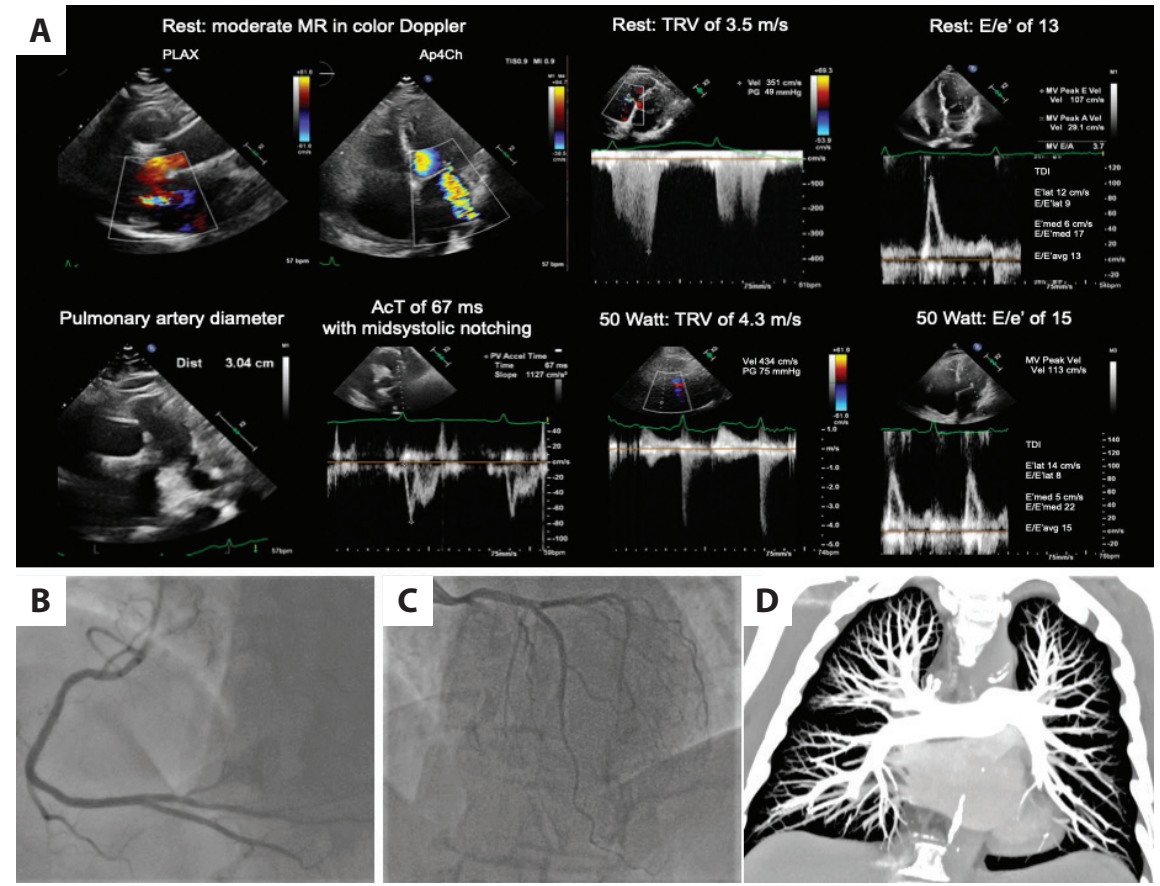

Figure 1. A. Bicycle exercise echocardiography showing a moderate mitral regurgitation at rest with TRV $3.5 \mathrm{~m} / \mathrm{s}$ and the transmitral early peak velocity (E) by pulsed wave Doppler over mitral annulus velocity (e') (E/e') 13 and a rapid increase in TRV (up to $4.3 \mathrm{~m} / \mathrm{s}$ at $50 \mathrm{Watt}$ ), TR severity (from mild to moderate) and RV basal diameter (from 3.8 to $4.4 \mathrm{~cm}$ ) at exertion (50 Watt). B, C. Coronary angiography demonstrating no significant coronary lesions in the right coronary artery (B) and a patent stent in the proximal left anterior descending artery (C). D. Computed tomography angiography with no pathological findings

Abbreviations: RV, right ventricle; TR, tricuspid regurgitation; TRV, tricuspid regurgitation peak velocity

$37 \mathrm{~mm} \mathrm{Hg}$, PAWP of $17 \mathrm{~mm} \mathrm{Hg}$, and PVR of 6.5 Wood units, indicating combined post- and pre-capillary PH due to LHD. HF therapy was optimized, and the patient was discharged for ambulatory care.

While a PAWP > $15 \mathrm{~mm}$ Hg confirms LHD-PH, values between 13-15 $\mathrm{mm} \mathrm{Hg}$ are considered borderline. The PAWP of $13 \mathrm{~mm} \mathrm{Hg}$ in the first RHC in our patient might have been due to diuretic treatment and a lower pulmonary blood flow secondary to pre-capillary "reactive" vascular disease resulting in lower LA pressure. The respiratory cycle also may have contributed to the differences in PAWP measurements. PAWP and LVEDP should ideally be measured the end-diastole, averaged for the respiratory cycle, and by using QRS gating, which brings them as close as possible to intrathoracic pressure correction. Intrathoracic pressure is approximately $3 \mathrm{~mm} \mathrm{Hg}$ at functional residual capacity in healthy resting individuals [4]. This pre-capillary component of $\mathrm{PH}$ in our patient might have led to predominating RV HF symptoms, as well as a significant increase in TRV with a disproportionately small increase in the $\mathrm{E} / \mathrm{e}^{\prime}$ ratio during exercise echocardiography. Caution is required before initiating targeted therapies not recommended in patients with PH-LHD [5].

\section{Article information}

Conflict of interest: None declared.

Open access: This article is available in open access under Creative Common Attribution-Non-Commercial-No Derivatives 4.0 International (CC BY-NC-ND 4.0) license, allowing to download articles and share them with others as long as they credit the authors and the publisher, but without permission to change them in any way or use them commercially. For commercial use, please contact the journal office at kardiologiapolska@ptkardio.pl.

\section{REFERENCES}

1. Galiè N, Humbert M, Vachiery JL, et al. 2015 ESC/ERS Guidelines for the Diagnosis and Treatment of Pulmonary Hypertension. Rev Esp Cardiol (Engl Ed). 2016; 69(2): 177, doi: 10.1016/j.rec.2016.01.002, indexed in Pubmed: 26837729

2. Rosenkranz $\mathrm{S}$, Gibbs J, Wachter $\mathrm{R}$, et al. Left ventricular heart failure and pulmonary hypertension. Eur Heart J. 2015; 37(12): 942-954, doi: 10.1093/eurheartj/ehv512, indexed in Pubmed: 26508169.

3. Vachiéry $\mathrm{JL}$, Tedford R, Rosenkranz $\mathrm{S}$, et al. Pulmonary hypertension due to left heart disease. Eur Respir J. 2019; 53(1): 1801897, doi: 10.1183/13993003.01897-2018, indexed in Pubmed: 30545974.

4. Naeije R, Chin K. Differentiating precapillary from postcapillary pulmonary hypertension. Circulation. 2019; 140(9): 712-714, doi: 10.1161/circulationaha.119.040295, indexed in Pubmed: 31449453.

5. Pieske B, Tschöpe C, de Boer R, et al. How to diagnose heart failure with preserved ejection fraction: the HFA-PEFF diagnostic algorithm: a consensus recommendation from the Heart Failure Association (HFA) of the European Society of Cardiology (ESC). Eur Heart J. 2019;40(40):3297-3317, doi: 10.1093/eurheartj/ehz641, indexed in Pubmed: 31504452. 